\title{
Recombination and clonal propagation in different populations of the lichen Lobaria pulmonaria
}

\author{
J-C Walser ${ }^{1}$, F Gugerli ${ }^{1}$, R Holderegger ${ }^{1}$, D Kuonen ${ }^{2}$ and C Scheidegger ${ }^{1}$ \\ ${ }^{1}$ WSL Swiss Federal Research Institute, Zürcherstrasse 111, CH-8903 Birmensdorf, Switzerland; ${ }^{2}$ Statoo Consulting, PO Box 107, \\ CH-1015 Lausanne, Switzerland
}

\begin{abstract}
Propagation, dispersal, and establishment are fundamental population processes, and are critical stages in the life cycle of an organism. In symbiotic organisms such as lichens, consisting of a fungus and a population of photobionts, reproduction is a complex process. Although many lichens are able to reproduce both sexually and asexually, the extent of vegetative propagation within local populations is unknown. We used six polymorphic microsatellite loci to investigate whether recombination is common in natural populations, and to assess if and how clonal reproduction influences the spatial genetic structure within populations of the epiphytic lichen species Lobaria pulmonaria. High genetic diversity within all 12 investigated populations and
\end{abstract}

evidence of recombination, from various tests, indicated that L. pulmonaria is a predominantly outcrossing species. Nevertheless, clonality occurred in all populations, but the presence of recurring multilocus genotypes influenced the spatial genetic structure only within low-density populations. This could be interpreted as indicative of genetic bottlenecks owing to increased habitat loss and disturbance. Consequently, for a predominantly outcrossing lichen species, exogenous factors might be substantially altering population processes and hence genetic structure.

Heredity (2004) 93, 322-329. doi:10.1038/sj.hdy.6800505

Published online 16 June 2004

Keywords: asexual propagation; dispersal; lichenised ascomycete; outcrossing; sexual reproduction; spatial autocorrelation

\section{Introduction}

Propagation, whether sexual or asexual, is a fundamental step in the life cycle of every single organism. Sexual reproduction enhances the number of different genotypes within populations and increases the probability of survival in a competitive and/or changing environment (Maynard Smith, 1978; Balloux et al, 2000), whereas asexual propagation, on the other hand, can be a successful evolutionary strategy for well-adapted genotypes in extreme but stable habitats (Murtagh et al, 2000). While our knowledge of mating systems and patterns in animals and plants is broad (eg, Jackson et al, 1996; Takebayashi and Morrell, 2001), we have only just started to investigate and understand them in symbiotic life forms such as lichens. Despite a few studies on sexual reproduction in lichens (Murtagh et al, 2000; Kroken and Taylor, 2001; Högberg et al, 2002), nothing is known about its importance as compared to clonal reproduction (through thallus fragments, soredia, or isidia) in natural populations. Therefore, the objectives of this study were (i) to investigate whether recombination, and hence outbreeding, is common in natural populations of lichens, and (ii) to determine how clonal reproduction influences the spatial genetic structure within populations.

Correspondence: J-C Walser, Department of Organismal Biology and Anatomy, The University of Chicago, 1027 East 57th Street, Chicago, IL 60637, USA. E-mail: jcwalser@uchicago.edu

Received 21 August 2003; accepted 23 March 2004; published online 16 June 2004
Recent developments of modern molecular markers allow the population genetic processes of lichens to be investigated. However, the few studies available so far suffer from various limitations (Walser et al, 2003). Some have focused on nuclear ribosomal DNA (nrDNA) amplified by fungus-specific primers (Bridge and Hawksworth, 1998) which, although sufficient for the analysis of major fungal lineages (Lutzoni et al, 2001), have the disadvantage of detecting rather low levels of intraspecific genetic variation (Bridge and Hawksworth, 1998; Zoller et al, 1999; Högberg et al, 2002). Greater variation has been detected with random amplified polymorphic DNA markers (RAPDs), allowing studies on breeding systems (Murtagh et al, 2000) and on the population structure of lichen-forming fungi (Dyer et al, 2001). In these RAPD studies, DNA has been isolated either from axenic fungal cultures or from thallus tissue free of photobionts (Crespo and Cubero, 1998; Heibel et al, 1999). As it is not possible to obtain algae-free material in lichen species that are asexual and for which the mycobiont is not cultivatable (Miao et al, 2001), anonymous DNA fingerprinting cannot provide specific results for lichenised fungi and is thus not universally applicable in mutualistic endosymbiotic systems. Highly variable, fungusspecific microsatellites would circumvent these problems. For Lobaria pulmonaria, several microsatellite loci have recently been developed (Walser et al, 2003), which suit the specific requirements of our study. Four of the 12 original primers used in this study were re-designed in order to shorten allele sizes, to avoid indels in the flanking regions, and to amplify loci in multiplex PCR. 


\section{Materials and methods}

\section{Species}

The foliose epiphytic lichen L. pulmonaria (L.) Hoffm. is widely distributed in circumboreal regions of the Northern Hemisphere and in South Africa (Yoshimura, 1971, $1998 \mathrm{a}, \mathrm{b})$. While L. pulmonaria has a large range and is still common in North America (Brodo et al, 2001), it is considered endangered in many parts of Europe (Wirth et al, 1996). Although it is described as both a sexually and clonally reproducing species, apothecia (fruit bodies with sexual propagules) are formed infrequently and populations with only a limited number of fungal genotypes appear to be nonsexual (Zoller et al, 1999). This correlation between genotypic diversity and fertility has been interpreted as evidence that L. pulmonaria might be self-sterile (heterothallic; Zoller et al, 1999).

\section{Sampling}

In total, 562 thalli of L. pulmonaria were sampled from nine populations in British Columbia, Canada, and from three populations in Switzerland (Table 1). We consid- ered a population as a patch of trees colonised by $L$. pulmonaria. Beyond the patch perimeter, the species did not occur locally. The samples from British Columbia were collected within three different zones (hypermari time, maritime, and intermontane; Goward, 1999) on a transect from the south coast of Vancouver Island to the interior of the province. These populations either occurred in old growth forests (eg, CS, PR, DC, CL, BL, or $\mathrm{OC}$ ) or in dense undisturbed forests (AY, TO, and BC). The samples from Switzerland were collected in comparatively large, but sparse populations in the Pre-Alps and the Jura Mountains, where anthropogenic disturbance has been minimal. Across an entire population, one thallus per tree was randomly taken from selected nearest neighbor trees. The distance between the host trees was measured, the area of the local population was calculated (Table 2), and the number of samples with apothecia was determined.

\section{Microsatellite analysis}

DNA was isolated according to Walser et al (2003) from approximately $20 \mathrm{mg}$ of cleaned marginal lobes per

Table 1 Locations and their geographic circumscriptions of the 12 studied populations of Lobaria pulmonaria

\begin{tabular}{|c|c|c|c|c|c|}
\hline Location & Code & Life zones/area & Altitude (m) & Latitude & Longitude \\
\hline \multicolumn{6}{|l|}{ Canada, British Columbia } \\
\hline Ayum Creek, Vancouver Island & AY & Hypermaritime $^{a}$ & 15 & $48^{\circ} 23^{\prime} 29^{\prime \prime} \mathrm{N}$ & $123^{\circ} 39^{\prime} 37^{\prime \prime} \mathrm{W}$ \\
\hline Chesterman Beach, Tofino & TO & Hypermaritime $^{a}$ & 5 & $49^{\circ} 06^{\prime} 47^{\prime \prime} \mathrm{N}$ & $125^{\circ} 53^{\prime} 31^{\prime \prime} \mathrm{W}$ \\
\hline Cape Scott Provincial Park & CS & Hypermaritime $^{a}$ & 5 & $50^{\circ} 40^{\prime} 27^{\prime \prime} \mathrm{N}$ & $128^{\circ} 16^{\prime} 32^{\prime \prime} \mathrm{W}$ \\
\hline Lakelse Lake Provincial Park & PR & Maritime $^{\mathrm{a}}$ & 105 & $54^{\circ} 22^{\prime} 54^{\prime \prime} \mathrm{N}$ & $128^{\circ} 31^{\prime} 52^{\prime \prime} \mathrm{W}$ \\
\hline Date Creek, Kispiox & DC & Maritime $^{\mathrm{a}}$ & 550 & $55^{\circ} 24^{\prime} 52^{\prime \prime} \mathrm{N}$ & $127^{\circ} 48^{\prime} 52^{\prime \prime} \mathrm{W}$ \\
\hline Clayton Falls, Bella Coola & $\mathrm{BC}$ & Maritime $^{\mathrm{a}}$ & 5 & $52^{\circ} 22^{\prime} 12^{\prime \prime} \mathrm{N}$ & $126^{\circ} 48^{\prime} 49^{\prime \prime} \mathrm{W}$ \\
\hline Carp Lake Provincial Park & $\mathrm{CL}$ & Intermontane $\mathrm{a}^{\mathrm{a}}$ & 860 & $54^{\circ} 52^{\prime} 08^{\prime \prime} \mathrm{N}$ & $123^{\circ} 15^{\prime} 39^{\prime \prime} \mathrm{W}$ \\
\hline Bowron Lake Provincial Park & BL & Intermontane ${ }^{a}$ & 910 & $53^{\circ} 15^{\prime} 19^{\prime \prime} \mathrm{N}$ & $121^{\circ} 21^{\prime} 03^{\prime \prime} \mathrm{W}$ \\
\hline Oregana Creek, Tumtum Lake & OC & Intermontane $^{\mathrm{a}}$ & 723 & $51^{\circ} 59^{\prime} 08^{\prime \prime} \mathrm{N}$ & $119^{\circ} 05^{\prime} 21^{\prime \prime} \mathrm{W}$ \\
\hline \multicolumn{6}{|l|}{ Switzerland } \\
\hline Taaren Wald, Toggenburg & TW & Pre-Alps & 1350 & $47^{\circ} 10^{\prime} 50^{\prime \prime} \mathrm{N}$ & $9^{\circ} 18^{\prime} 15^{\prime \prime} \mathrm{E}$ \\
\hline Murgtal, Walensee & MT & Pre-Alps & 1280 & $47^{\circ} 03^{\prime} 52^{\prime \prime} \mathrm{N}$ & $9^{\circ} 11^{\prime} 51^{\prime \prime} \mathrm{E}$ \\
\hline Marchairuz, Jura Mountains & UZ & Jura Mountains & 1200 & $46^{\circ} 29^{\prime} 57^{\prime \prime} \mathrm{N}$ & $6^{\circ} 10^{\prime} 21^{\prime \prime} \mathrm{E}$ \\
\hline
\end{tabular}

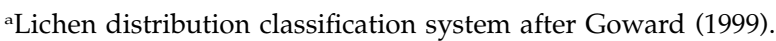

Table 2 Number of samples $(N)$, area in acres of the investigated populations of Lobaria pulmonaria, local population density (N/area), mean number of alleles $(A)$, effective mean number of alleles $\left(A_{\mathrm{e}}\right)$, and percentage of different genotypes $(M)$, and of fertile samples (samples with apothecia)

\begin{tabular}{|c|c|c|c|c|c|c|c|}
\hline Population & $\mathrm{N}$ & Area (acres) & $\mathrm{N} /$ Area & A & $\mathrm{A}_{e}$ & $\mathrm{M}(\%)$ & Apothecia (\%) \\
\hline AY & 39 & 30 & 1.30 & 7.8 & 5.1 & 79 & 13 \\
\hline TO & 47 & 80 & 0.59 & 7.2 & 4.3 & 62 & 19 \\
\hline CS & 50 & 30 & 1.67 & 7.7 & 4.8 & 52 & 42 \\
\hline PR & 50 & 10 & 5.00 & 8.7 & 4.4 & 90 & 42 \\
\hline DC & 52 & 10 & 5.20 & 7.3 & 3.4 & 92 & 25 \\
\hline $\mathrm{BC}$ & 50 & 10 & 5.00 & 10.5 & 5.7 & 90 & 10 \\
\hline CL & 51 & 50 & 1.02 & 6.3 & 3.1 & 53 & 4 \\
\hline BL & 49 & 10 & 4.90 & 7.2 & 3.3 & 90 & 2 \\
\hline $\mathrm{OC}$ & 52 & 40 & 1.30 & 8.7 & 4.2 & 92 & 10 \\
\hline TW & 52 & 380 & 0.14 & 7.8 & 4.4 & 52 & 8 \\
\hline MT & 38 & 680 & 0.06 & 5.3 & 3.6 & 47 & 11 \\
\hline UZ & 32 & 80 & 0.40 & 6.8 & 3.8 & 53 & 0 \\
\hline Mean \pm SE CA & 48.9 & 30 & $2.89 \pm 0.68$ & $7.9 \pm 0.4$ & $4.3 \pm 0.3$ & $78 \pm 6$ & $19 \pm 5$ \\
\hline Mean \pm SE CH & 40.7 & 380 & $0.20 \pm 0.10$ & $6.6 \pm 0.7$ & $3.9 \pm 0.2$ & $51 \pm 2$ & $6 \pm 3$ \\
\hline Mean \pm SE total & 46.8 & 120 & $2.21 \pm 0.62$ & $7.6 \pm 0.4$ & $4.2 \pm 0.2$ & $71 \pm 6$ & $16 \pm 4$ \\
\hline
\end{tabular}

Means and standard errors are given for British Columbia in Canada (CA), for Switzerland (CH), and for the total sample set (total). For population codes, see Table 1. 
thallus. Six microsatellite loci were studied ( $L P u 03$, LPu09, LPu15, LPu16, LPu20, and LPu27; Walser et al, 2003), and four of the original primers were re-designed in order to shorten allele sizes or to avoid indels in the flanking regions (Table 3). The loci were amplified in two multiplex polymerase chain reactions (PCRs) with each containing three primer pairs $(L P u 03 / L P u 09 / L P u 15$ and LPu16/LPu20/LPu27). Subsequent amplification and fragment analysis, using an automated capillary sequencer, followed protocols given by Walser et al (2003). As DNA was isolated from thallus material, the proportion of fungal DNA was unknown and varied among samples. In each $30-\mu \mathrm{l}$ amplification reaction, $3 \mu \mathrm{l}$ of genomic DNA extract was used. In addition to Walser et al (2003), the lengths of the 19 alleles at locus LPu09 that were longer than $400 \mathrm{bp}$ were partially checked with the size standard ROX-1000 (Applied Biosystems) and subsequently extrapolated. Samples with missing microsatellite data were excluded $(n=3)$.

\section{Statistical analysis}

Mean allele number $(A)$ and mean effective number of alleles $\left(A_{\mathrm{e}}\right)$ were calculated following Hartl and Clark (1997).

Since the fungal partner of a lichen is haploid and has only one allele per locus, tests for recombination involve the examination of allelic associations between different loci (Maynard Smith et al, 1993). Panmixia would imply that alleles at all loci, except for physically proximate loci, were randomly associated with each other. However, even genes on different chromosomes may deviate from random association due to different factors such as genetic drift, selection, clonal reproduction, and/or nonrandom mating (Lewontin, 1988). We used a $\chi^{2}$ test with $P$-values computed by Monte Carlo permutations with 10000 replicates and adjusted with Hommel's method for multiple comparisons (Hommel, 1988) to test for the presence of a significant association between pairs of loci per population (with and without recurring genotypes). We also calculated the normalized measure for total disequilibrium described by Hedrick (1987) and the extended Fisher exact probability test under the null hypothesis of no association between the two tested loci per population as implemented in ARLEQUIN (Schneider et al, 2000).
We also used the standardized index of association $\left(I_{\mathrm{A}}\right)$ (Maynard Smith et al, 1993) to check for recombination or clonality within populations. From the distribution of mismatch values, an observed variance $\left(V_{\mathrm{D}}\right)$ was calculated and compared with the expected variance $\left(V_{\mathrm{e}}\right)$ under linkage equilibrium (Maynard Smith et al, 1993; Haubold et al, 1998; Haubold and Hudson, 2000). The null hypothesis $\left(I_{\mathrm{A}}=0\right.$, ie, random association of alleles) was tested by 1000 permutations and $P$-values again adjusted with Hommel's (1988) method. These calculations were performed once with and once without recurring genotypes.

If a lichen-forming fungus reproduces clonally (through mitosis) or by homothallic mating, the entire genome is effectively linked since there is no segregation and no re-assortment of alleles. We therefore also calculated pairwise comparisons of microsatellite loci in addition to the multilocus associations described above. A lack of association between any pair of loci may be interpreted as being due to recombination, whereas linkage or homoplasy might cause deviations from expected genotypic frequencies under random mating in some pairs of loci.

The spatial genetic structure within populations was analyzed based on multilocus genotypes (Smouse and Peakall, 1999) using GENALEX (Peakall and Smouse, 2001) to investigate the effects of the dispersal of vegetative and sexual propagules. We performed a spatial autocorrelation test for distance classes with equal sample sizes and used the stepwise mutation model based on sum-of-squared-number-of-repeat differences between two genotypes (Slatkin, 1995) as a measure of genetic distance. Spatial autocorrelation analysis was carried out twice: once with and once without recurring genotypes. Deviation from the null hypothesis $H_{0}: r=0$ was determined by 1000 permutations. In addition to this analysis, we also tested for correlation between geographic and genetic distances within populations of L. pulmonaria using Mantel tests with 1000 permutations calculated with the R package.

Spearman's rank correlation coefficients were used to estimate the associations between local population area (log-transformed) and percentage of different genotypes $(M)$ or fertile samples, and between percentage of fertile samples and mean allele number $(A)$ or mean effective number of alleles $\left(A_{\mathrm{e}}\right)$.

Table 3 Microsatellite loci of Lobaria pulmonaria included in this study

\begin{tabular}{|c|c|c|c|c|c|}
\hline Locus & Primer sequence $\left(5^{\prime}-3^{\prime}\right)$ & $\mathrm{T}_{a}\left({ }^{\circ} \mathrm{C}\right)$ & Label & Allele size range (bp) & Number of alleles \\
\hline LPu03 & $\begin{array}{l}\text { F: GGCTGCAATGATGACTAGGA } \\
\text { R: CACCCTGGTGTTGACTGCTA }\end{array}$ & 55 & NED & 187-193 & 4 \\
\hline LPu09 & $\begin{array}{l}\text { F: AGCCTGGAGTTCAGACAACC } \\
\text { R: ATCTTGTCTTGGCGCTTCTG }\end{array}$ & 55 & $6 \mathrm{FAM}$ & $181-640$ & 34 \\
\hline LPu15 & $\begin{array}{l}\text { F: CAAAATACCTGAATGGATGT } \\
\text { R: CTGAGGCAACACTCTACAGC }\end{array}$ & 55 & HEX & 149-203 & 20 \\
\hline LPu16 & $\begin{array}{l}\text { F: GCCTGCCAAAGAATACAGCA } \\
\text { R: TGTCGATGTCTTGCCTGAAC }\end{array}$ & 57 & HEX & $186-260$ & 23 \\
\hline LPu20 & $\begin{array}{l}\text { F: CTCTGCCGCTCGGGTTACAT } \\
\text { R: TGCCAGTACTGCAATGTGGT }\end{array}$ & 57 & NED & $161-241$ & 32 \\
\hline LPu27 & $\begin{array}{l}\text { F: GCTCATGCTCCACATCTGAC } \\
\text { R: CATGCTCTTCCATTCACAGC }\end{array}$ & 57 & $6 \mathrm{FAM}$ & $170-206$ & 14 \\
\hline
\end{tabular}

Primer sequence (F: forward; R: reverse), annealing temperature $\left(T_{\mathrm{a}}\right)$ in multiplex-PCR, dye used for $5^{\prime}$ fluorescent labelling of forward primer, range of allele sizes, and number of alleles detected. The six loci are described in Walser et al (2003), but four primers (given in bold) were re-designed in order to shorten allele sizes or to avoid indels in the flanking regions. 


\section{Results}

Microsatellite diversity and frequency of apothecia Genetic diversity within local populations of L. pulmonaria, based on the six microsatellite loci, was high. Among the 562 individuals analyzed, we found 405 different genotypes, $75 \%$ of which occurred only once. The number of alleles per locus and population ranged from one for locus $L P u 27$ in population DC to 22 for $L P u 20$ in population BC. The mean number of alleles per population $(A)$ ranged from 5.3 to 10.5 and the mean effective number of alleles $\left(A_{\mathrm{e}}\right)$ ranged from 3.1 to 5.7 (Table 2). The percentages of different genotypes $(M)$ were uniformly low within the Swiss populations ( $\approx 50 \%$ ), but varied from 52 to $92 \%$ among the populations from British Columbia (Table 2). The percentages of fertile specimens (bearing apothecia) ranged from $0 \%$ (population UZ) to a maximum of $42 \%$ (populations CS and PR; Table 2). There was a significant negative association (Spearman coefficient, $r_{s}=-0.766, P=0.005$ ) between $M$ and the local population area. In contrast, we found neither a significant correlation between the percentage of fertile samples (apothecia) and the mean allele number $(A)$ or the mean effective number of alleles $\left(A_{\mathrm{e}}\right)$, nor between the percentage of fertile samples and local population area.

\section{Recombination and clonality}

All three measurements of linkage disequilibrium, the $\chi^{2}$ test, Hedrick's normalized measure for total disequilibrium, and the extended Fisher exact probability test, yielded similar results. Only the results for the $\chi^{2}$ test are presented (Table 4). About 5\% of all pairwise comparisons in British Columbia and 7\% in Switzerland rejected the null hypothesis of independence of loci. The results were not congruent across loci and suggested linkage disequilibrium between loci $L P u 16 / L P u 27$ and $L P u 20 /$ LPu27 (Table 4).

In the pairwise and the multilocus index of association $I_{\mathrm{A}}$ analysis (Maynard Smith et al, 1993) and when all samples were considered, the null hypothesis (ie, no association between two loci) was rejected in 32 and $69 \%$ of all pairwise comparisons in the populations of British Columbia and Switzerland, respectively (Table 5a). Excluding recurring genotypes, the null hypothesis was rejected in only $5 \%$ of the pairwise comparisons for British Columbia and in $4 \%$ for Switzerland (Table 5b). In accordance with the linkage disequilibrium analysis given above, a somewhat higher number of $I_{\mathrm{A}}$-values was significantly different from zero for the loci $L P u 16$, $L P u 20$, and LPu27 (Table 5b).

\section{Spatial genetic structure}

The spatial autocorrelation analysis showed different genetic structures in the Swiss and British Columbia populations of L. pulmonaria. In the Swiss populations, positive autocorrelation values $(r)$ were found in the first distance classes when all samples (with recurring genotypes) were used in the analysis (Figure 1). In population MT, a particularly high coefficient of $r>0.6$ was detected in the shortest distance class. However, this positive autocorrelation in the Swiss populations disappeared when the recurring genotypes were excluded from the analysis (Figure 1). In contrast, we found no significant genetic structure in any of the nine $L$. pulmonaria populations from British Columbia, irrespective of whether recurring genotypes were taken into account or not. As an example, the respective correlograms for population TO are presented in Figure 1.

In accordance with these results, significant and positive Mantel correlations were only found between the geographic and genetic distances of Swiss populations when all samples were included (data not shown). However, correlations were not significant when the reduced data set without recurring genotypes was used.

\section{Discussion}

\section{Recombination}

Our data confirm that L. pulmonaria, like many other lichens, has the ability to disperse both by means of sexual and asexual propagules (Murtagh et al, 1999; Zoller et al, 1999; Kroken and Taylor, 2001). Although the occurrence of apothecia per se is evidence for sexual

Table 4 Linkage disequilibrium among pairs of loci within populations of Lobaria pulmonaria: $\chi^{2}$-values with $P<0.05$ (based on Monte Carlo permutations with Hommel's adjustment) are in bold

\begin{tabular}{|c|c|c|c|c|c|c|c|c|c|c|c|c|c|c|c|}
\hline \multirow[t]{3}{*}{ Population } & \multicolumn{15}{|c|}{ Locus } \\
\hline & \multicolumn{5}{|c|}{ LPu03 } & \multicolumn{4}{|c|}{ LPu09 } & \multicolumn{3}{|c|}{ LPu15 } & \multicolumn{2}{|c|}{ LPu16 } & \multirow{2}{*}{$\frac{L P u 20}{L P u 27}$} \\
\hline & LPu09 & LPu15 & LPu16 & LPu20 & LPu27 & LPu15 & LPu16 & LPu20 & LPu27 & LPu16 & LPu20 & LPu27 & LPu20 & LPu27 & \\
\hline AY & 31.13 & 13.51 & 16.58 & 30.73 & 0.88 & 54.92 & 53.61 & 117.90 & 24.14 & 46.44 & 86.41 & 7.82 & 143.59 & 28.35 & 38.98 \\
\hline TO & 8.88 & 4.43 & 5.29 & 13.62 & 1.92 & 43.53 & 60.18 & 110.23 & 27.82 & 39.89 & 101.15 & 12.82 & 145.00 & 70.08 & 59.15 \\
\hline CS & 30.33 & 14.38 & 15.89 & 20.40 & 3.30 & 35.10 & 50.31 & 91.49 & 8.78 & 64.93 & 107.85 & 24.52 & 132.46 & $\overline{48.40}$ & 52.00 \\
\hline PR & 14.25 & 10.79 & 9.22 & 7.97 & 3.14 & 94.46 & 222.33 & 127.32 & 49.07 & 53.68 & 60.26 & $\overline{7.04}$ & 162.98 & 8.67 & $\overline{6.49}$ \\
\hline DC & 12.16 & 2.37 & 17.07 & 2.91 & NA & 86.29 & 89.89 & 70.59 & NA & 64.67 & 52.60 & NA & $\overline{58.45}$ & NA & NA \\
\hline BC & 13.12 & 37.56 & 35.36 & 32.74 & 1.45 & 118.83 & 147.33 & 248.39 & 5.29 & 165.72 & 141.70 & 5.27 & 314.52 & 19.68 & 36.96 \\
\hline CL & 4.57 & 4.57 & 27.00 & 27.00 & 12.98 & 77.70 & 128.25 & 27.12 & 3.67 & 44.16 & 14.88 & 1.97 & 69.53 & 16.07 & 19.71 \\
\hline BL & 15.04 & 6.27 & 6.93 & 3.86 & 0.13 & 64.18 & 95.34 & 57.08 & 13.98 & 66.89 & 84.68 & 21.49 & 130.45 & 44.00 & 44.00 \\
\hline OC & 6.26 & 14.61 & 6.96 & 11.40 & 0.14 & 70.93 & 209.64 & 206.17 & 83.47 & 62.47 & 51.13 & 4.93 & 168.17 & 52.67 & 96.00 \\
\hline TW & 14.05 & 46.13 & 27.65 & 43.88 & 19.15 & 39.02 & 45.55 & 52.26 & $\overline{18.21}$ & $\underline{116.04}$ & 87.38 & 62.45 & 99.28 & $\underline{97.63}$ & $\overline{65.93}$ \\
\hline MT & 6.04 & 21.43 & 2.98 & 14.50 & 1.39 & 25.33 & 20.10 & 59.19 & 4.90 & 9.85 & 40.21 & 1.93 & 29.16 & $\overline{10.27}$ & 14.68 \\
\hline UZ & 7.43 & 10.42 & 13.62 & 29.10 & 12.21 & 45.47 & 55.66 & 80.99 & 36.43 & 52.21 & 40.87 & 42.74 & 66.87 & $\overline{37.78}$ & 41.56 \\
\hline
\end{tabular}

NA: not assessed since population DC was monomorphic at locus $L P u 27$. For population codes see Table 1. 
Table 5 Standardized indices of association $\left(I_{\mathrm{A}}\right)$ between pairs of loci and over all loci in populations of Lobaria pulmonaria

\begin{tabular}{|c|c|c|c|c|c|c|c|c|c|c|c|c|c|c|c|c|}
\hline & \multicolumn{16}{|c|}{ Locus } \\
\hline & \multicolumn{5}{|c|}{ LPu03 } & \multicolumn{4}{|c|}{ LPu09 } & \multicolumn{3}{|c|}{ LPu15 } & \multicolumn{2}{|c|}{ LPu16 } & \multirow{2}{*}{$\frac{L P u 20}{L P u 27}$} & \multirow[b]{2}{*}{ Over all lo } \\
\hline & LPu09 & LPu15 & LPu16 & LPu20 & LPu27 & LPu15 & LPu16 & LPu20 & $L P u 27$ & LPu16 & LPu20 & LPu27 & LPu20 & LPu 27 & & \\
\hline \multicolumn{17}{|c|}{ (a) With recurring genotypes } \\
\hline AY & 0.082 & 0.113 & 0.065 & 0.056 & -0.161 & 0.143 & 0.080 & 0.141 & 0.141 & 0.160 & 0.136 & 0.025 & 0.130 & 0.154 & 0.033 & 0.382 \\
\hline TO & 0.046 & 0.019 & 0.060 & 0.107 & 0.150 & $\overline{0.178}$ & 0.406 & $\overline{0.438}$ & 0.183 & $\overline{0.254}$ & $\overline{0.275}$ & -0.012 & 0.615 & & 0.327 & $\overline{1.015}$ \\
\hline CS & 0.041 & -0.030 & $\overline{0.003}$ & -0.019 & -0.011 & $\overline{0.266}$ & $\overline{0.296}$ & $\overline{0.363}$ & $\overline{0.138}$ & $\overline{0.362}$ & $\overline{0.505}$ & & 0.549 & & $\overline{0.348}$ & $\overline{1.215}$ \\
\hline PR & -0.003 & 0.058 & -0.031 & -0.046 & 0.047 & $\overline{0.042}$ & $\overline{0.059}$ & $-\overline{0.007}$ & $\overline{0.019}$ & $-\overline{0.021}$ & $\overline{0.013}$ & $-\overline{0.024}$ & .321 & -0.061 & $-\overline{0.027}$ & 118 \\
\hline $\mathrm{DC}$ & 0.025 & -0.095 & -0.035 & 0.000 & NA & -0.002 & -0.029 & -0.076 & NA & -0.011 & 0.058 & NA & .039 & & NA & 339 \\
\hline $\mathrm{BC}$ & -0.014 & 0.097 & -0.045 & 0.006 & -0.102 & 0.035 & 0.001 & -0.011 & -0.152 & 0.056 & $-0 .($ & & 0.092 & & 0.088 & .004 \\
\hline CL & 0.047 & 0.117 & 0.111 & 0.252 & 0.778 & 0.302 & 0.266 & -0.001 & -0.015 & 0.118 & -0.031 & 0.0 & $\overline{0.303}$ & 04 & $\overline{0.331}$ & 0.825 \\
\hline $3 \mathrm{~L}$ & 040 & 0.034 & $-\overline{0.035}$ & $\overline{0.058}$ & $-\overline{0.035}$ & $\overline{0.067}$ & -0.023 & 0.001 & 0.054 & -0.004 & 0.066 & 0.0 & $\overline{0.206}$ & 73 & .156 & $\overline{0.268}$ \\
\hline $\mathrm{DC}$ & 0 & 078 & -0.001 & 0.015 & -0.047 & 0.010 & 0.107 & 0.008 & 0.1 & -0.010 & -0.065 & -0.022 & $\overline{154}$ & & 0.226 & $\overline{223}$ \\
\hline TW & 0.023 & 242 & 0.146 & 0.102 & 0.347 & 0.372 & $\overline{0.367}$ & 0.287 & $\overline{0.1}$ & 0.459 & 0.345 & & $\overline{423}$ & & .240 & $\overline{1.266}$ \\
\hline MT & 0.027 & $\overline{0.124}$ & -0.099 & 0.117 & $-\overline{0.138}$ & $\overline{0.322}$ & $\overline{0.349}$ & $\overline{0.362}$ & $\overline{0.149}$ & $\overline{0.199}$ & $\overline{0.375}$ & $\overline{0.199}$ & $\overline{0.377}$ & $\overline{0.4}$ & $\overline{0.245}$ & $\overline{0.947}$ \\
\hline UZ & -0.042 & 0.125 & 0.049 & 0.193 & 0.186 & $\overline{0.186}$ & $\overline{0.318}$ & $\overline{0.490}$ & 0.247 & $\overline{0.184}$ & $\overline{0.168}$ & $\overline{0.170}$ & $\overline{0.357}$ & $\overline{0.387}$ & $\overline{0.211}$ & $\overline{1.043}$ \\
\hline \multicolumn{17}{|c|}{ (b) Without recurring genotypes } \\
\hline AY & 0.118 & 0.026 & 0.007 & 0.002 & -0.140 & & 0.017 & -0.009 & & & 0.011 & -0.048 & -0.023 & 0.094 & -0.047 & \\
\hline TO & 0.023 & -0.048 & -0.048 & -0.033 & -0.024 & 0.063 & 0.050 & 0.057 & 0.021 & 0.037 & 0.044 & -0.025 & 0.214 & & 0.281 & 0.299 \\
\hline CS & 0.098 & 0.052 & 0.015 & -0.032 & -0.026 & 0.076 & -0.002 & 0.055 & -0.060 & 0.067 & 0.130 & 0.143 & $\overline{0.035}$ & $\overline{0.359}$ & $\overline{0.205}$ & $\overline{0.398}$ \\
\hline PR & 0.009 & 0.036 & -0.034 & -0.072 & 0.058 & 0.010 & 0.040 & -0.007 & 0.000 & -0.050 & -0.009 & -0.0 & 0.302 & $-\overline{0.068}$ & $-\overline{0.022}$ & 057 \\
\hline DC & 0.004 & -0.081 & -0.002 & 0.039 & NA & -0.007 & -0.047 & -0.081 & NA & -0.020 & 0.029 & NA & $\overline{0.040}$ & NA & NA & -0 \\
\hline $\mathrm{BC}$ & -0.032 & 0.082 & -0.049 & -0.008 & -0.092 & 0.050 & -0.015 & -0.045 & -0.147 & 0.035 & -0.039 & -0.007 & 0.040 & 0.011 & 0.078 & -0.059 \\
\hline CL & -0.047 & .061 & 0.098 & 0.314 & 0.663 & 0.055 & -0.030 & -0.035 & -0.077 & -0.066 & -0.050 & -0.0 & 0.209 & 66 & 0.437 & 0.475 \\
\hline BL & 0.060 & 0.016 & -0.046 & 0.035 & -0.039 & 0.069 & -0.043 & -0.011 & 0.055 & -0.034 & 0.052 & 0.093 & 0.180 & 0.076 & 0.157 & 0.215 \\
\hline OC & -0.017 & 105 & -0.017 & 0.010 & -0.051 & 0.007 & 0.065 & -0.002 & 0.108 & -0.017 & -0.078 & -0.0 & 0.102 & 0.089 & 0.230 & 0.169 \\
\hline TW & -0.018 & 209 & 0.017 & 0.034 & & & 0.146 & -0.024 & -0.016 & & -0.007 & & 0.119 & & 0.070 & 0.444 \\
\hline MT & -0.075 & 0.025 & -0.109 & -0.060 & -0.142 & -0.050 & 0.076 & -0.052 & -0.077 & & -0.003 & -0.0 & -0.067 & 0.277 & 0.080 & -0.046 \\
\hline UZ & -0.212 & 0.006 & -0.093 & 0.180 & 0.171 & -0.065 & 0.024 & -0.069 & 0.120 & 0.145 & -0.103 & 0.154 & 0.080 & 0.065 & -0.035 & 0.145 \\
\hline
\end{tabular}

Significance values $(P<0.05$; based on 1000 permutations with Hommel's adjustment) are in bold. NA: not assessed owing to monomorphism at locus $L P u 27$. For population codes see Table 1.

reproduction, it provides neither information pertaining to the effective establishment of sexually derived individuals nor any indication about the relative importance of sexual versus asexual reproduction under natural conditions. While sexual processes can occur between genetically identical cells or hyphae in selffertile (homothallic) fungi, recombination in self-sterile (heterothallic) lichen species leads to segregation and reassortment of alleles at different loci. When recurring multilocus genotypes are included and the hypothesis of panmixia is rejected, this suggests nonrandom associations among samples within populations. Conversely, acceptance of the hypothesis, when recurring genotypes are not present, is usually regarded as evidence for random mating (Maynard Smith et al, 1993; Xu et al, 1999). Together, this would indicate that both recombination and clonal growth influence population genetic structure. In the present study, the index of association, as well as the conventional linkage disequilibrium tests, pointed to substantial rates of recombination in $L$. pulmonaria both in local populations from British Columbia and Switzerland. Therefore, we can conclude that L. pulmonaria is primarily outcrossing. A recent study of six L. pulmonaria populations in Switzerland (Zoller et al, 1999) came to the same conclusion and also showed that populations with higher genetic variation in the nuclear ribosomal DNA ( $\mathrm{nDNA}$ ) region were more likely to form sexual propagules than less variable populations. In contrast, our data did not reveal any significant correlation between the percentage of fertile samples and the number of alleles or the percentage of different genotypes per population. For example, in population BL, $90 \%$ of all samples showed different genotypes, but only $2 \%$ were fertile, and in population UZ, despite the absence of apothecia, evidence for recombination based on the microsatellite markers was found. However, our samples were not necessarily representative of the whole populations as there may well be fertile thalli within the tree canopy that were not collected. A recent study showed that multiple colonization of a single tree may occur in dense populations of L. pulmonaria (Walser et al, 2003), and therefore the number of fertile samples within a local population might be underestimated because only one randomly taken thallus per tree was assessed for the presence of apothecia.

Generally, populations from Switzerland had lower densities of thalli than those from British Columbia and might well represent the remains of formerly larger, denser, and more fertile populations. Furthermore, the relation between fertile samples and measures of genetic diversity is influenced by the perennial life cycle of lichens and by the fact that apothecia in L. pulmonaria occur at later life stages (Ramstad and Hestmark, 2001; Denison, 2003). It is therefore possible that different age structures within populations studied led to the differences in the observed frequency of apothecia. However, the data given in Table 2 suggest that the percentage of fertile samples per population might be different between Switzerland and British Columbia or even between the zones within British Columbia. These 

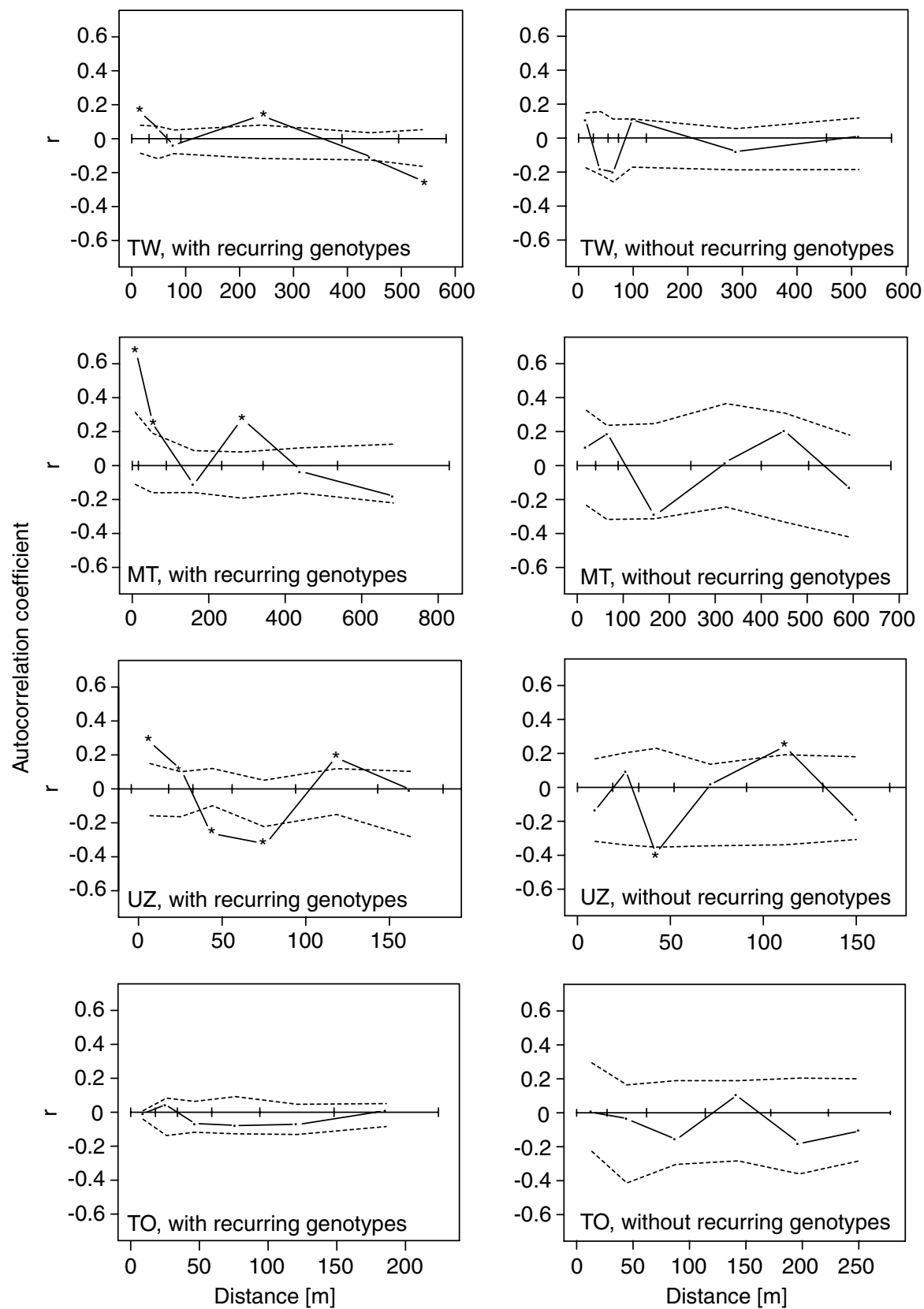

Figure 1 Examples of multilocus spatial autocorrelation in Lobaria pulmonaria; populations from Switzerland (TW, MT, and UZ) and British Columbia, Canada (TO). For each population, two correlograms with and without recurring genotypes are shown. The 95\% confidence intervals are indicated by dotted lines, and values significantly different from zero (based on 1000 permutations) are presented by asterisk. Note the different scales of the $x$-axis owing to equal sample size within distance classes but, therefore, different scales per population

findings suggest that the frequency and the development of apothecia are governed by exogenous factors, for example, oceanity, which is, however, confounded with altitude in our study.

\section{Genetic structure}

A recent study on Letharia vulpina showed that samples from North America had a higher genetic variation at eight single-nucleotide polymorphism sites (SNPs) than did samples from Sweden or Italy. It was thus concluded that L. vulpina should be outcrossing in North America, but effectively clonal in Europe (Högberg et al, 2002).
Similarly, our data suggested that populations of L. pulmonaria from British Columbia also harbored a significantly larger number of genotypes than did Swiss populations (Table 2). This lower genotypic diversity in the Swiss populations may be attributed to historical bottlenecks (Zoller et al, 1999). In addition, we also found that populations from Vancouver Island, with the exception of population CL, had a lower genotypic diversity than did populations from the mainland. This could be due to the spatial isolation of these populations (Walser et al, unpublished data). Interestingly, the number of different genotypes showed a negative association with the local population area, which might 
indicate that denser populations support a higher number of genotypes.

Furthermore, our data points to substantial clonal propagation at a small spatial scale within the three Swiss populations (Walser, in press). The different spatial genetic structures between populations on the two continents may be attributed to population density and history. For example, the populations from British Columbia occur in less disturbed forest ecosystems compared to the Swiss populations, which could have led to higher local densities, overlapping generations, and higher numbers of different genotypes even at a small spatial scale. Interestingly, Gu et al (2001) found that the spatial patterns of L. pulmonaria in Finland were more clumped in managed than in virgin forests. Although they did not examine spatial genetic structure, their results, together with ours, indicate that population history can influence the within-population spatial patterns.

\section{Conclusions}

Earlier studies on sexual reproduction in lichens examined the correlation between sexual reproduction and recombination (Zoller et al, 1999; Murtagh et al, 2000; Kroken and Taylor, 2001; Högberg et al, 2002). Our research has extended these studies by investigating clonal reproduction and its influence on spatial genetic structure within natural populations. The high genetic diversity within local populations and evidence of recombination from the association of alleles suggests that L. pulmonaria is a predominantly outcrossing species, despite the small number of apothecia that are present in a population. Nevertheless, clonality occurs in all investigated populations, with autocorrelation analysis indicating that only the genetic structure of the Swiss populations was influenced by clonal propagation. Certain population characteristics, namely density and levels of disturbance, are different between the Swiss populations and those from North America, and might explain the contrasting extent and prevalence of clonal propagation between continents. Such an intercontinental difference was also found in a recent study on another lichen species, with greater evidence for clonal spread in European populations compared to populations from North America (Högberg et al, 2002). This was interpreted as evidence for population genetic bottlenecks, and it was hypothesized that the European populations originated from their North American counterparts via long-distance dispersal of vegetative propagules. For L. pulmonaria, analysis of genetic differentiation between populations from British Columbia and Switzerland and a study on dispersal capacity of vegetative propagules do not support such a hypothesis (Walser et al, 2003; Walser et al, unpublished data). However, given that L. pulmonaria has suffered a significant decline in Europe within the last few decades (Hallingbäck and Martinsson, 1987) and that the Swiss populations are of lower density, our results could also be interpreted as indicative of genetic bottlenecks within Switzerland, owing to increased habitat loss and disturbance. Consequently, for predominantly outcrossing lichen species, exogenous factors, such as disturbance or fragmentation, might substantially alter population processes and hence genetic structure.

\section{Acknowledgements}

We thank Trevor Goward and Andy MacKinnon for accommodation, lively discussion, and field assistance. We are also grateful to Phil LePage, Davide Cuzner, and Traci Leys-Schirok from the British Columbia Forest Service for their support. We are indebted to Susan E Hoebee, the two reviewers and the subject editor for their constructive comments on the manuscript. This research was funded by the Swiss National Science Foundation (SNF 31-59241.99) and is associated with its research program NCCR Plant survival, PS6.

\section{References}

Balloux F, Brunner H, Lugon-Moulin N, Hausser J, Goudet J (2000). Microsatellites can be misleading: an empirical and simulation study. Evolution 54: 1414-1422.

Bridge PD, Hawksworth DL (1998). What molecular biology has to tell us at the species level in lichenized fungi. Lichenologist 30: 307-320.

Brodo IM, Duran Sharnoff S, Sharnoff S (2001). Lichens of North America. Yale University Press: London.

Crespo A, Cubero OF (1998). A molecular approach to the circumscription and evaluation of some genera segregated from Parmelia s. lat. Lichenologist 30: 369-380.

Denison WC (2003). Apothecia and ascospores of Lobaria oregana and Lobaria pulmonaria investigated. Mycologia 95: 513-518.

Dyer PS, Murtagh GJ, Crittenden PD (2001). Use of RAPD-PCR DNA fingerprinting and vegetative incompatibility tests to investigate genetic variation within lichen-forming fungi. Symbiosis 31: 213-229.

Goward T (1999). The Lichens of British Columbia. British Colombia Ministry of Forests: Victoria.

Gu WD, Kuusinen M, Konttinen T, Hanski I (2001). Spatial pattern in the occurrence of the lichen Lobaria pulmonaria in managed and virgin boreal forests. Ecography 24: 139-150.

Hallingbäck T, Martinsson PO (1987). The retreat of two lichens, Lobaria pulmonaria and L. scrobiculata, in the district of Gäsene (SW Sweden). Windahlia 17: 27-32.

Hartl LH, Clark AG (1997). Principles of Population Genetics, 3rd edn. Sinauer: Sunderland.

Haubold B, Hudson RR (2000). LIAN 3.0. Detecting linkage disequilibrium in multilocus data. Bioinformatics 16: 847-848.

Haubold B, Travisano M, Rainey PB, Hudson RR (1998). Detecting linkage disequilibrium in bacterial populations. Genetics 150: 1341-1348.

Hedrick PW (1987). Gametic disequilibrium measures-proceed with caution. Genetics 117: 331-341.

Heibel E, Lumbsch HT, Schmitt I (1999). Genetic variation of Usnea filipendula (Parmeliaceae) populations in western Germany investigated by RAPDs suggests reinvasion from various sources. Am J Bot 86: 753-757.

Högberg N, Kroken S, Thor G, Taylor JW (2002). Reproductive mode and genetic variation suggest a North American origin of European Letharia vulpina. Mol Ecol 11: 1191-1196.

Hommel G (1988). A stagewise rejective multiple test procedure based on a modified Bonferroni test. Biometrika 75: 383-386.

Jackson J, Buss L, Cook R (1996). Population Biology and Evolution of Clonal Organisms. Yale University Press: New Haven.

Kroken S, Taylor JW (2001). Outcrossing and recombination in the lichenized fungus Letharia. Fungal Genet Biol 34: 83-92.

Lewontin RC (1988). On measures of gametic disequilibrium. Genetics 120: 849-852.

Lutzoni F, Pagel M, Reeb V (2001). Major fungal lineages are derived from lichen symbiotic ancestors. Nature 411: 937-940.

Maynard Smith J (1978). The Evolution of Sex. Cambridge University Press: Cambridge.

Maynard Smith J, Smith NH, Orourke M, Spratt BG (1993). How clonal are bacteria. Proc Natl Acad Sci USA 90: 4384-4388. 
Miao V, Coeffet-LeGal MF, Brown D, Sinnemann S, Donaldson G, Davies J (2001). Genetic approaches to harvesting lichen products. Trends Biotechnol 19: 349-355.

Murtagh GJ, Dyer PS, Crittenden PD (2000). Reproductive systems - sex and the single lichen. Nature 404: 564.

Murtagh G, Dyer P, McClure P, Crittenden P (1999). Use of randomly amplified polymorphic DNA markers as a tool to study variation in lichen-forming fungi. Lichenologist 31: 257-267.

Peakall R, Smouse PE (2001). GENALEX. Genetic analysis in Excel Release 5. Australian National University: Canberra.

Ramstad S, Hestmark G (2001). Population structure and sizedependent reproductive effort in Umbilicaria spodochroa. Mycologia 93: 453-458.

Schneider S, Roessli D, Excoffier L (2000). ARLEQUIN. A software for population genetic data analysis Release 2.000. University of Geneva: Geneva.

Slatkin M (1995). A measure of population subdivision based on microsatellite allele frequencies. Genetics 139: 457-462.

Smouse PE, Peakall R (1999). Spatial autocorrelation analysis of individual multiallele and multilocus genetic structure. Heredity 82: 561-573.

Takebayashi N, Morrell PL (2001). Is self-fertilization an evolutionary dead end? Revisiting an old hypothesis with genetic theories and a macroevolutionary approach. Am J Bot 88: 1143-1150.

Walser J-C (in press). Molecular evidence for limited dispersal of vegetative propagules in an epiphytic lichen. Am J Bot.
Walser J-C, Sperisen C, Soliva M, Scheidegger C (2003). Fungusspecific microsatellite primers of lichens: application for the assessment of genetic variation on different spatial scales in Lobaria pulmonaria. Fungal Genet Biol 40: 72-82.

Wirth V, Scholler H, Scholz P, Ernst G, Feuerer T, Gnuchtel A et al (1996). Rote Liste der Flechten (Lichenes) der Bundesrepublik Deutschland. In: Rote Listen der Pflanzen der Bundesrepublik Deutschland. Schriftenr Vegetationsk. 28, pp 307-368.

Xu JP, Mitchell TG, Vilgalys R (1999). PCR-restriction fragment length polymorphism (RFLP) analyses reveal both extensive clonality and local genetic differences in Candida albicans. Mol Ecol 8: 59-73.

Yoshimura I (1971). The genus Lobaria of Eastern Asia. J Hattori Bot Lab 34: 231-364.

Yoshimura I (1998a). Lung lichen and their vegetation in Japan and other regions. In: Kondratyuk SY, Coppins BJ (eds) Lobarion Lichens as Indicators of the Primeval Forests of the Eastern Carpathians. Ukrainian Phytosociological Centre: Kiev, pp 53-63.

Yoshimura I (1998b). Vainio and Lobaria, old and modern concepts. In: Marcelli MP, Ahti T (eds) Recollecting Edvard August Vainio. CETESB: Sao Paulo, Brazil, pp 85-94.

Zoller S, Lutzoni F, Scheidegger C (1999). Genetic variation within and among populations of the threatened lichen Lobaria pulmonaria in Switzerland and implications for its conservation. Mol Ecol 8: 2049-2059. 